\title{
SELECTION OF OIL PALM MALE PARENTS FOR OPTIMAL PLANTING DENSITY ESTIMATED FROM MATURE CROWN SURFACE
}

\author{
BREURE, $C \mathrm{~J}^{*}$ and SIREGAR, M M${ }^{\star}$
}

\begin{abstract}
Our study on selecting pisifera male parents aims at determining yield per palm as well as the optimal planting density of the tenera offspring. The data pattern came from dura $x$ pisifera testcrosses, planted at 135 and 160 palms ha-1 in North Sumatra, Indonesia, from which the breeding values of 15 pisifera parents of Ghana origin are estimated. Optimal palm densities were assessed from the leaf surface at mature canopy, obtained from the product of number of green leaves with the (asymptotic) maximum leaf area (0.95 L-max), inferred from a logistic growth curve fitted through leaf area values versus palm age. The time to reach the optimum values ranged between 5.5 to 7.9 years after planting. Amount of light under the palms, measured by the vigor of Mucuna cover crop, scored 50 and 67 months after planting (cc-score), considerably varied among pisifera. The clear negative correlation between yield and cc-score reveals that male parents selected for yield during the early years of production may generate tenera offspring palms that are highly lightcompetitive later on. To circumvent this drawback, this study suggests to select pisifera parents for yield per hectare at optimal palm density instead of yield per palm.
\end{abstract}

Keywords: pisifera selection, optimal planting density, leaf area index for maximum bunch yield.

Date received: 1 April 2019; Sent for revision: 3 May 2019; Accepted: 29 September 2019.

\section{INTRODUCTION}

Selection of oil palm parents should take into account not only the yield per palm but also the expected optimum planting density, i.e. the density giving the highest cumulative yield per hectare, as argued by Hardon et al. (1972); Breure and Corley (1983).

Furthermore, the Nigerian Institute for Oil Palm Research (NIFOR) records quoted by Sparnaaij (1969) indicate that progenies differing in vegetative vigor may have unequal optimal planting densities. Support came from Sly and Chapas (1963), who reported that (individual) progenies are only able to

PT. ASD-Bakrie Oil Palm Seed Indonesia,

J Besar Air Joman,

Pasar IX, Kisaran 21263

North Sumatra, Indonesia.

E-mail: breurekees@gmail.com achieve highest yield per hectare at specific planting densities. Statistically significant differences in optimal density between clones were reported by Corley and Donough (1992), which provides further evidence that progenies need specific palm densities to express the full yield potential. It is therefore timely to obtain the actual optimal planting density of dura x pisifera (tenera) offspring descending from individual parent palms.

Suggestions have been made to take growth parameters into account in the selection of parent palms, in addition to yield per palm (Hardon et al., 1972). Including growth parameters became feasible when Hardon et al. (1969) and Corley et al. (1971) had evolved non-destructive measurements for estimating leaf area and dry matter production of oil palm. It was suggested that particularly leaf area is an important parameter for estimating potential yield per hectare. 
Breure and Corley (1983) confirmed that young palms selected for high yield per palm tend to have a considerably higher leaf area than the remaining ones. In other words, they are highly competitive palms and would probably not yield well in a more uniform population of equally vigorous palms. They concluded that, instead, selection for high bunch index, i.e. the proportion of total dry matter used for bunch production, is more effective. These young palms yielded well at a later phase when inter-palm competition for light has increased, in contrast to palms exclusively selected for high yield.

Smith et al. (1996) found that in the early years of production optimal density was mainly related to rachis length: palms with short rachises compete less than those with longer rachises. Later on, when leaves were overlapping, the optimum was more related to leaf area.

Breure (2010) showed that optimal density could be determined at an early stage. Therefore, the leaf area at maximum crown size (L-max) was applied, which was estimated from a logistic growth curve fitted to annual leaf area values up to only eight years after planting. Multiplying L-max by the number of fronds gives the total leaf area per palm, which together with the optimal leaf area index (LAI), i.e. total leaf surface per hectare for maximum yield per hectare, was used to estimate the optimal palm density at mature crown surface.

In the present study, mature leaf surface per palm was estimated from the product of 0.95 L-max, instead of the asymptotic value, and the actual number of green fronds at a mature canopy, as reported by Gerritsma and Soebagyo (1999). To estimate the time to reach the optimum planting density, we also calculated the time after planting to reach $0.95 \mathrm{~L}-\max \left(\mathrm{t}_{0.95}\right)$.

Increasing LAI by closer planting of the palms enhances light interception by the foliage. Initially, the increment of intercepted light by the leaf surface proportionally benefits the amount of gross carbon dioxide $\left(\mathrm{CO}_{2}\right)$ assimilation, and hence, the rate of conversion of absorbed solar radiation to carbohydrates $\left(\mathrm{CH}_{2} \mathrm{O}\right)$. Individual leaves are, however, light-saturated already at about $30 \%$ of full sunlight (Gerritsma, 1988), so the main part of light absorbed beyond this level is wasted. At a certain level of LAI, therefore, diminished light use efficiency due to poor light distribution over the various layers of the canopy (as a result of closer spacing) restricts a further increase in carbohydrates for total dry matter (TDM) production. Since vegetative dry matter (VDM) production still continues to increase linearly at that stage, a further increment of LAI reduces bunch dry matter (BDM) production. This intrinsic relationship of TDM, VDM and BDM with LAI is depicted in Figure 1, which is based on results of a palm density experiment with AVROS material in Papua New Guinea (PNG), as reported by Breure (1988). Figure 1 shows the curve of $\mathrm{CH}_{2} \mathrm{O}$ incorporated in TDM production and the linear curve of those incorporated in VDM, plotted against LAI. The distance between both regression lines, which is the amount of carbohydrates $\left(\mathrm{CH}_{2} \mathrm{O}\right)$ available for BDM, shows its largest size at LAI of $4.5^{2}$, to be regarded as the specific LAI for producing optimal yield per hectare. This value is slightly lower than LAI of 5 , a value commonly characterised by a closed green canopy (Lövenstein et al., 1995).

It should be clear that optimum LAI mainly depends on the extent of light penetration through

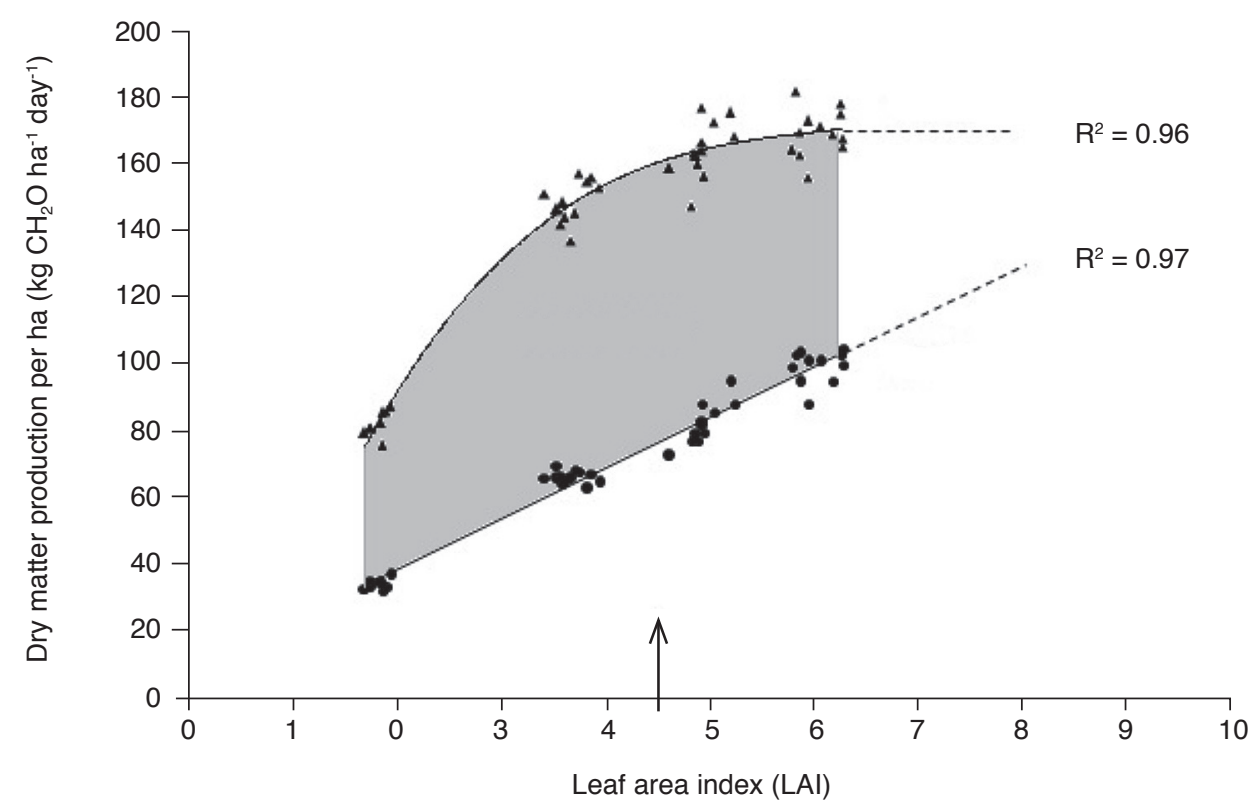

Figure 1. Relation between leaf area index (LAI) and assimilates ( $\mathrm{gg} \mathrm{CH}_{2} \mathrm{O}$ ha ${ }^{-1}$ day $\left.{ }^{-1}\right)$ for total dry matter (TDM), vegetative dry matter (VDM) and bunch dry matter (BDM ). Points are various sub-plot values for each of the four palm densities $\left(56,110,148\right.$ and 186 palms ha $\left.{ }^{-1}\right)$ for the period six to nine years after planting [adopted from Breure (1988)]. Optimum yield per hectare is indicated by a vertical arrow and occurs at LAI $=4.5$. 
the canopy. Oil palm has a spherical leaf angle arrangement, being a random arrangement of the leaf angles, in which lower leaf layers substantially contribute to overall crop assimilation, as a result of a favourable light distribution. So, we may assume that possible (minor) differences in canopy structure among the mixture of dura x pisifera offspring palms derived from individual Ghana pisifera as well as between the offspring from pure AVROS and Ghana origins have a negligible effect on the extent of light distribution, and hence, on optimal LAI.

Light under the palms is inferred from the vigor of the Mucuna covercrop (referred to as cc-score) before canopy closure. Cover crop forms the lowest layer of the total intercepting green leaf surface, so a high cc-score indicates a low light interception by the oil palm canopy. Since, as shown in Figure 1, VDM has priority in the allocation of carbohydrates, the cc-score is expected to have an inverse relationship with yield.

Breure (2010) postulated that, based on mean L-max values of a set of Ghana pisifera tested in an experiment in South Sumatra, Indonesia, Ghana planting material can be planted at 160 palms ha- $^{-1}$. The present study validates whether this general recommendation applies for individual Ghana pisifera. For comparing optimum planting densities of pisifera, we used an optimum LAI for maximum yield per hectare of 4.5 , being the equivalent of 45000 $\mathrm{m}^{2}$ leaf surface of the palms per hectare.

The ultimate goal of the present study is to select pisifera parents for yield per hectare of the tenera offspring, based on the product of (estimated) optimal planting density and yield per palm adjusted to the novel optimal density. Finally, the amount of light under the palms, as indirectly defined by the vigor of the Mucuna cover crop before its closure, is used to study the relationship between estimated light absorbed by the oil palm foliage and yield.

\section{MATERIALS AND METHODS}

\section{Plant Material}

This study focuses on selecting 15 pisifera ( $P$ codes) of Ghana origin, derived from highlyinbred parental crosses, developed at Kade Oil Palm Research Centre, Ghana, using genetic material introduced from NIFOR. The pisifera were part of the male parents of tenera progenies, generated by ASD from dura $\mathrm{x}$ pisifera crosses, aimed to estimate the breeding values of the parents. The crossing scheme for generating the progenies was according to an alpha design (Patterson et al., 1978). Each dura was pollinated by two pisifera palms and each pisifera pollinated eight dura palms.

The progenies were arranged in 16-palm plots, with two replicates each planted at a density of
135 palms ha-1 and 160 palms ha-1; the latter plots were surrounded by a single guard row. The data pattern for individual pisifera was thus based on eight dura x pisifera crosses with 64 palms per cross, resulting in a total of 512 records. The dura $\mathrm{x}$ pisifera progenies were planted at Kisaran, North Sumatra, in 2010. A vigorous, pure, Mucuna legume crop was established under the palms in all plots, as shown in Figure 2.

\section{Environmental Conditions}

Growing conditions at Kisaran are very favourable for oil palm. Soils are alluvial hydromorphic, largely derived from Toba volcanic ash (Foster, 2011), and uniform. Annual rainfall is about $3500 \mathrm{~mm}$, which is well distributed during the year, and $6 \mathrm{hr}$ bright sunshine per day.

\section{Data Collection}

Yield. Fruit bunch yield was recorded for seven years from the start of production in 2012.

Leaf area. The area of the first fully expanded youngest leaf was annually estimated during the first eight years after field planting, following the method as described by Breure (2017). A total of 10 leaves were measured (one extra at the start and one in the middle of the eight-year period). A logistic curve was fitted through leaf area values of offspring from each pisifera parent. From this curve, the asymptotically attained maximum leaf area (L-max) and the time to reach $0.95 \mathrm{~L}-\mathrm{max}\left(\mathrm{t}_{0.95}\right)$ were estimated. The method is described by Breure and Verdooren (1995).

Number of fronds. This was measured at 7.2 years after planting. For determining a final (stable) mature leaf surface at a later date, we used a constant

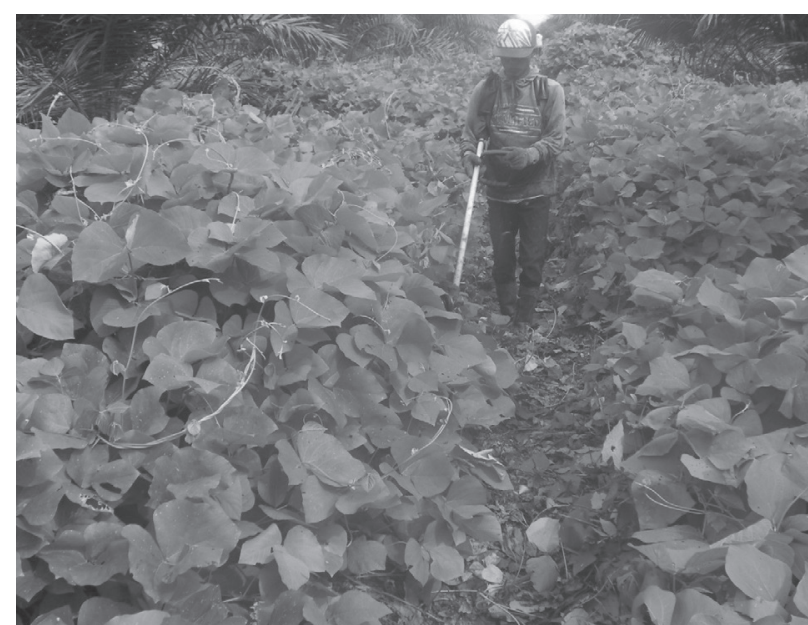

Figure 2. Vigorous Mucuna cover crop one year after planting the oil palm seedlings. 
number of 36 fronds per palm, as obtained under estate standards of frond pruning by Gerritsma and Soebagyo (1999).

Canopy light penetration. This was inferred from the vigor of the Mucuna cover crop below the canopy at 50 and 67 months after planting (about the time when the canopy had just closed). The global appearance of vigor around individual palms was scored from 3 (vigorous Mucuna cover) to 0 (absence of Mucuna cover) as depicted in Figures 3 and 4, respectively. Records for individual palms were averaged per plot (referred to as cc-score). Recording was done by several observers, who were carefully calibrated on the index of cc-scoring.

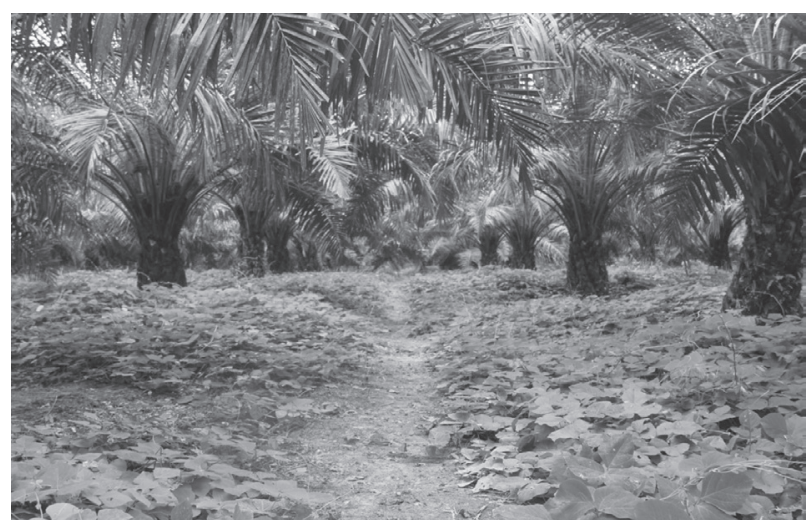

Figure 3. Plot of Mucuna cover crop with cc-score 3.

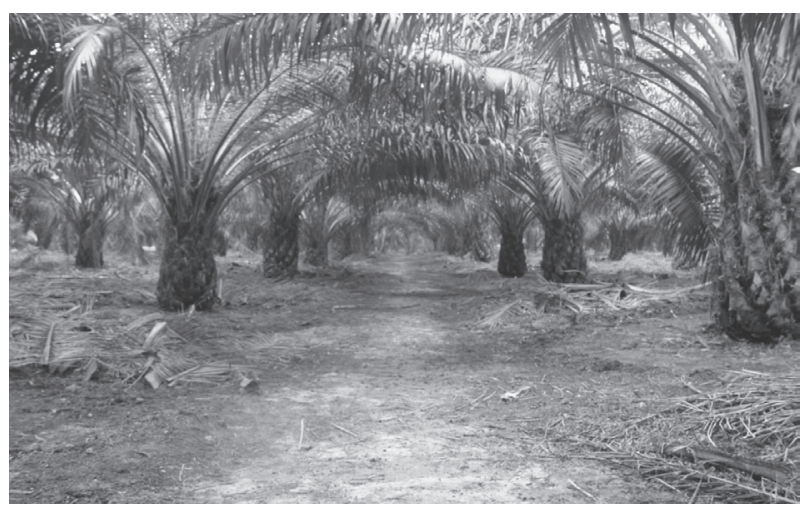

Figure 4. Plot of Mucuna cover crop with cc-score 0.

\section{Estimating Optimal Planting Density}

The optimal densities (D) of the tenera offspring progenies, derived from individual pisifera, were estimated for a mature leaf surface from the product of $0.95 \mathrm{~L}$-max and 36 fronds per palm by applying an optimal LAI of 4.5:

$$
\mathrm{D}=(4.5 \times 10000) /[(0.95 \mathrm{~L}-\max ) \times 36]
$$

\section{Yield Per Hectare}

The yield per hectare was calculated as the product of the estimated optimal planting density and the yield per palm. The latter was adjusted, for individual pisifera, to the novel optimal planting densities based on the linear interpolation of cumulative yield per palm obtained at the 135 and 160 palms ha-1.

\section{Data Processing}

For each of the 15 pisifera parents, the General Combining Ability or Breeding Value, i.e. the additive genotypic effect of the selection traits, was estimated from mean plot values of the progeny test.

\section{RESULTS}

\section{Leaf Area}

The asymptotic maximum leaf area (L-max) ranged from $8.41 \mathrm{~m}^{2}$ for pisifera $\mathrm{P} 6$ to $9.46 \mathrm{~m}^{2}$ for pisifera P30 (Table 1). Optimal densities at mature leaf surface ranged from 139 (P30) to 156 (P6 and P34) palms ha-1.

Table 1 also presents for each pisifera the period in years $\left(\mathrm{t}_{0.95}\right)$ when $0.95 \mathrm{~L}$-max, and hence optimal palm density, is attained. The period varied between 5.5 and 7.9 years after planting (P7 versus P28). There was a non-significant positive relationship $(\mathrm{r}=0.35)$ of L-max with $\mathrm{t}_{0.95}$, indicating that the variation in L-max is only slightly due to the period of area expansion.

Due to a difference in speed of leaf expansion, the mean leaf area between years 2 to 5 did virtually not correspond with L-max $(\mathrm{r}=0.18)$. The poor relationship is illustrated by comparing P7 and P28. Both pisifera have nearly the same L-max (9.01 versus $9.17 \mathrm{~m}^{2}$ ), but differ considerably in mean leaf area for years 2 to $5\left(6.20 \mathrm{~m}^{2}\right.$ versus $5.09 \mathrm{~m}^{2}$; Table 1$)$. More interesting is that P7 reached $0.95 \mathrm{~L}$-max much earlier than P28 (5.5 versus 7.9 years after planting). Figure 5 depicts the data of leaf area expansion over the years for both pisifera.

The mean number of fronds on the palms, observed 7.2 years after planting, ranged between 39 and 41 among pisifera (with an average of 40 fronds).

\section{Yield Per Palm and Per Hectare at Optimal Palm Density}

Table 2 presents the yield $\left(\mathrm{kg} \mathrm{palm}^{-1}\right)$ for the individual pisifera, together with the ranking order. Mean yield per palm density (being 160 and 135 palms ha ${ }^{-1}$ ) was 1281 versus $1414 \mathrm{~kg} \mathrm{palm}^{-1}$. Assuming a linear decrement of yield per palm as a function of planting density, for each individual pisifera, the yield per palm was corrected for the novel (optimal) palm density ( $c f$. Table 1) based on an interpolation of yield at the two densities. 
TABLE 1. RACHIS LENGTH (cm), MAXIMUM LEAF

AREA (L-max), TIME TO REACH 0.95 L-MAX $\left(t_{0.95}\right)$, MEAN LEAF AREA FOR YEARS TWO TO FIVE AND ESTIMATED OPTIMAL PALM DENSITY (palm ha" $\left.{ }^{-1}\right)$ FOR 15 GHANA Pisifera

\begin{tabular}{|c|c|c|c|c|c|}
\hline $\begin{array}{c}\text { Pisifera } \\
\text { codes }\end{array}$ & $\begin{array}{c}\text { Rachis } \\
\text { length } \\
\text { (cm) }\end{array}$ & $\begin{array}{c}\text { L-max } \\
\left(\mathrm{m}^{2}\right)\end{array}$ & $\begin{array}{c}t_{0.95} \\
\text { (years) }\end{array}$ & $\begin{array}{c}\text { Mean } \\
\text { leaf area } \\
2-5 \text { years } \\
\left(\mathrm{m}^{2}\right)\end{array}$ & $\begin{array}{c}\text { Optimal } \\
\text { density } \\
\text { (palms } \\
\text { ha-1) }^{-1}\end{array}$ \\
\hline 6 & 457 & 8.41 & 6.5 & 5.34 & 156 \\
\hline 34 & 451 & 8.44 & 6.8 & 5.37 & 156 \\
\hline 32 & 447 & 8.47 & 6.6 & 5.36 & 155 \\
\hline 23 & 446 & 8.61 & 6.6 & 5.37 & 153 \\
\hline 2 & 446 & 8.65 & 5.8 & 5.75 & 152 \\
\hline 47 & 454 & 8.73 & 6.4 & 5.74 & 151 \\
\hline 31 & 435 & 8.82 & 7.7 & 5.02 & 149 \\
\hline 29 & 440 & 8.83 & 7.5 & 5.01 & 149 \\
\hline 35 & 468 & 8.85 & 6.7 & 5.41 & 149 \\
\hline 7 & 477 & 9.01 & 5.5 & 6.20 & 146 \\
\hline 12 & 472 & 9.13 & 6.8 & 5.59 & 144 \\
\hline 28 & 448 & 9.17 & 7.9 & 5.09 & 143 \\
\hline 11 & 467 & 9.27 & 6.3 & 5.98 & 142 \\
\hline 27 & 446 & 9.29 & 7.5 & 5.32 & 142 \\
\hline 30 & 463 & 9.46 & 7.5 & 5.47 & 139 \\
\hline Mean & 454 & 8.88 & 6.8 & 5.47 & 148 \\
\hline Min & 435 & 8.41 & 5.5 & 5.01 & 139 \\
\hline Max & 477 & 9.46 & 7.9 & 6.20 & 156 \\
\hline
\end{tabular}

adjusted yield per palm and optimal density. As an example, yield per palm for P34 was clearly lower than for P30 (1342 versus $1426 \mathrm{~kg}$ palm ${ }^{-1}$ ). Applying the optimal density calculation, however, there was only a minor difference between P34 and P30 (204 versus $206 \mathrm{t} \mathrm{ha}^{-1}$ ).

Based on yield per hectare, P32 is now clearly the best parent instead of P30, which would be conventionally selected for yield per palm (1426 versus $1403 \mathrm{~kg} \mathrm{palm}^{-1}$ for P30 and P32, respectively).

\section{Relationship between Yield per Palm with cc-score}

As expected, the inverse relationship of yield per palm with cc-score was highly significant $(\mathrm{r}=-0.74 ; \mathrm{p}=0.01)$. Figure 6 shows, for the combined results of the two densities, the yield for the first seven years of production versus ccscore for each pisifera. Note, for example, the data of P30, for which a high yield is combined with a low cc-score and vice versa with the data of P29. In other words, the offspring of pisifera palm P30 with the highest light interception (as inferred from the cc-score) generates the highest yield. In contrast, the offspring of palm P29 with the lowest light interception produces the lowest yield.

TABLE 2. BREEDING VALUES OF YIELD ( $\left.\mathrm{kg} \mathrm{palm}^{-1}\right)$, ADJUSTED YIELD FOR THE NOVEL DENSITIES

$\left(\mathrm{kg} \mathrm{palm}^{-1}\right)$ AND YIELD AT OPTIMUM PALM DENSITY $\left(\mathrm{t} \mathrm{ha} \mathrm{h}^{-1}\right)$, TOGETHER WITH THEIR RANKING (R), FOR 15 GHANA Pisifera DURING THE FIRST SEVEN YEARS OF PRODUCTION

\begin{tabular}{|c|c|c|c|c|c|c|c|}
\hline \multirow{2}{*}{$\begin{array}{l}\text { Pisifera } \\
\text { codes }\end{array}$} & \multicolumn{3}{|c|}{ Yield (kg palm-1) } & \multirow{2}{*}{$\mathbf{R}$} & \multirow{2}{*}{$\begin{array}{l}\text { Adjusted yield } \\
\left(\mathrm{kg} \mathrm{palm}^{-1}\right)\end{array}$} & \multirow{2}{*}{$\begin{array}{l}\text { Yield } \\
\left(\mathrm{t} \mathrm{ha}^{-1}\right)\end{array}$} & \multirow{2}{*}{$\mathbf{R}$} \\
\hline & $160 \mathrm{ha}^{-1}$ & $135 \mathrm{ha}^{-1}$ & Total $^{*}$ & & & & \\
\hline 32 & 1365 & 1433 & 1403 & 5 & 1378 & 214 & 1 \\
\hline 2 & 1307 & 1497 & 1411 & 3 & 1367 & 208 & 2 \\
\hline 11 & 1319 & 1509 & 1416 & 2 & 1456 & 207 & 3 \\
\hline 30 & 1328 & 1511 & 1426 & 1 & 1481 & 206 & 4 \\
\hline 12 & 1294 & 1495 & 1403 & 4 & 1421 & 205 & 5 \\
\hline 34 & 1296 & 1379 & 1342 & 10 & 1310 & 204 & 6 \\
\hline 7 & 1286 & 1472 & 1376 & 6 & 1390 & 203 & 7 \\
\hline 6 & 1268 & 1330 & 1303 & 12 & 1277 & 200 & 8 \\
\hline 28 & 1316 & 1431 & 1369 & 7 & 1392 & 200 & 9 \\
\hline 31 & 1299 & 1383 & 1342 & 9 & 1336 & 199 & 10 \\
\hline 47 & 1245 & 1449 & 1343 & 8 & 1320 & 199 & 11 \\
\hline 35 & 1256 & 1377 & 1321 & 11 & 1311 & 195 & 12 \\
\hline 23 & 1246 & 1300 & 1274 & 13 & 1261 & 193 & 13 \\
\hline 29 & 1186 & 1342 & 1256 & 14 & 1254 & 187 & 14 \\
\hline 27 & 1208 & 1295 & 1253 & 15 & 1272 & 180 & 15 \\
\hline Mean & 1281 & 1414 & 1349 & - & 1348 & 200 & - \\
\hline Min & 1186 & 1295 & 1253 & - & 1254 & 180 & - \\
\hline Max & 1365 & 1511 & 1426 & - & 1481 & 214 & - \\
\hline
\end{tabular}

Note: *Breeding values based on all four replicates.

Table 2 also presents the values of the adjusted yield $\left(\mathrm{kg} \mathrm{palm}^{-1}\right)$ and yield per hectare $\left(\mathrm{t} \mathrm{ha}^{-1}\right)$, along with the ranking order.

Evidently, the ranking order of yield per palm for individual pisifera considerably deviates from that of yield per hectare, based on the product of

\section{Factors Affecting cc-score}

A multiple regression analysis is employed, in which mean rachis length and leaf area for years two to five (corresponding to the canopy size that exerted an effect upon Mucuna vigor) are used as 


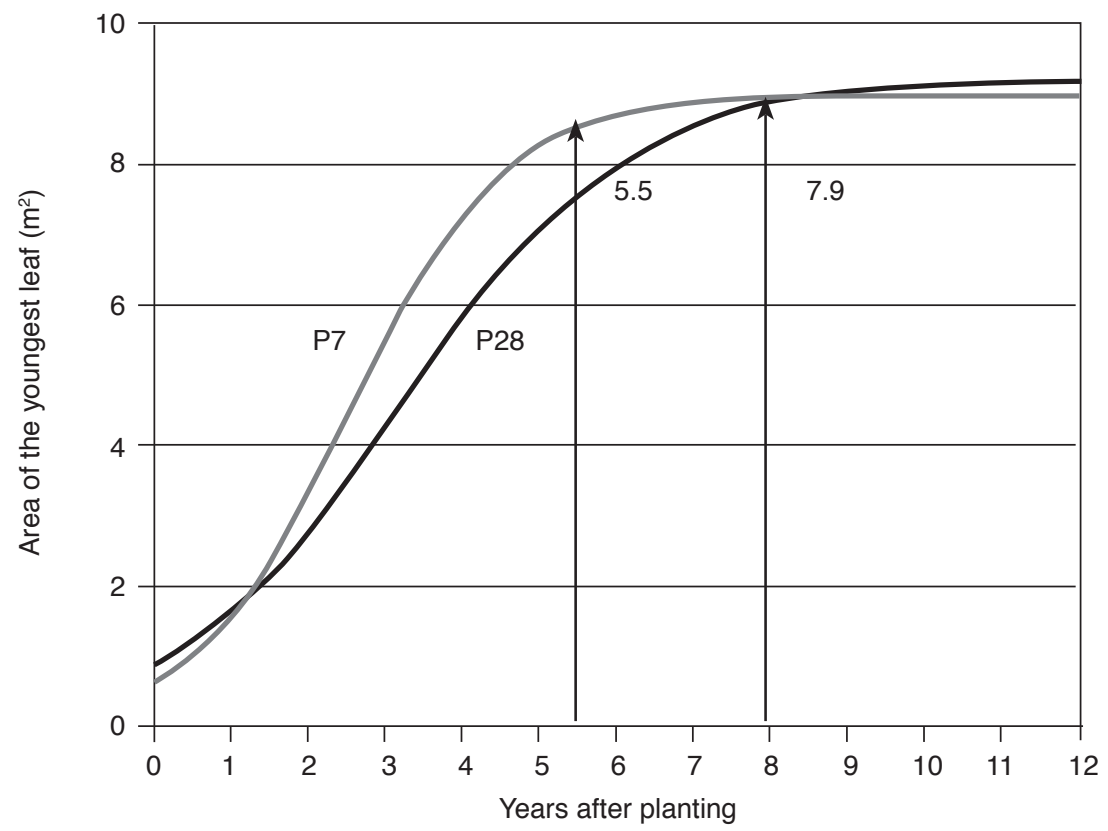

Figure 5. Leaf area versus time (years after planting) for pisifera codes (P) 7 and 28 of Ghana origin. The time to reach $0.95 L-\max \left(t_{0.95}\right)$ is indicated by a vertical arrow.

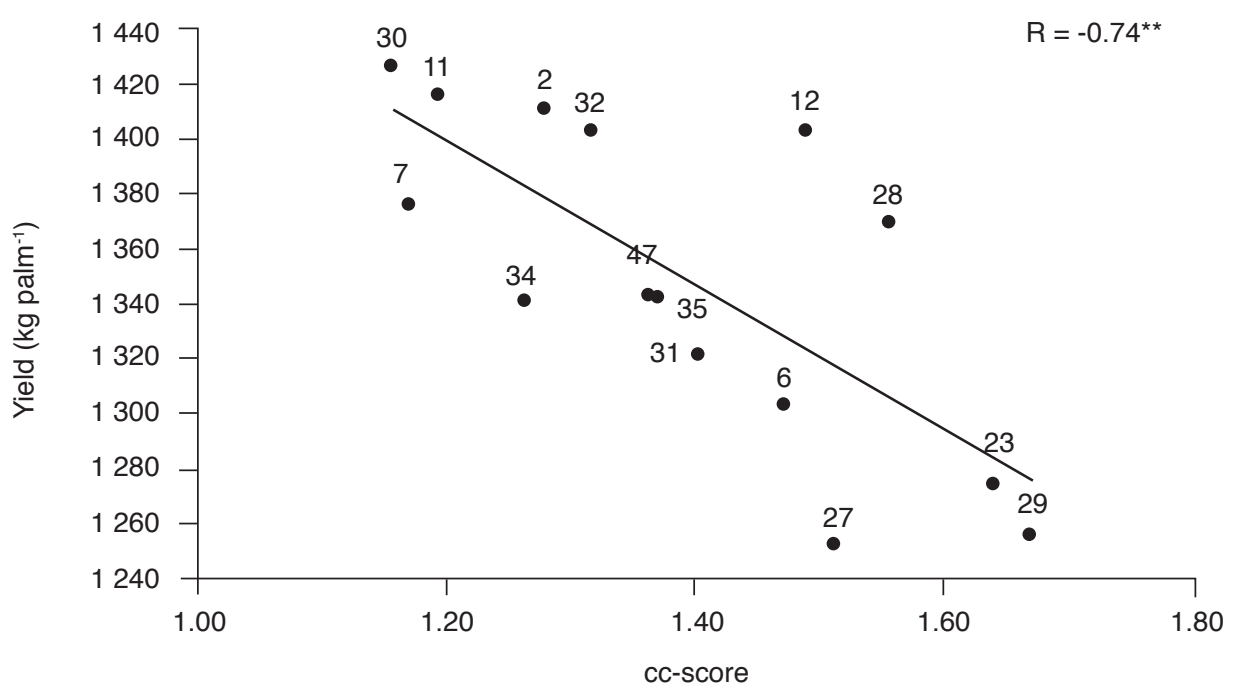

Figure 6. Yield ( $\left.\mathrm{kg} \mathrm{palm}^{-1}\right)$ during the first seven years of production vs. cc-score for 15 Ghana pisifera.

predictors of cc-score. The result revealed that the cc-score is only significantly affected by leaf area $(\mathrm{r}=0.65 ; \mathrm{P}=0.01)$, which acts upon the light penetration through the canopy.

\section{DISCUSSION}

\section{Yield Per Hectare}

Our investigation proves that it makes sense to focus on the optimal planting densities for tenera offspring descending from individual pisifera parents. Accordingly, pisifera parents can be selected for potential yield per hectare instead of yield per palm (cf. Table 2). Obtaining the optimal density is also essential for recommending companies that plant the tenera offspring descending from individual pisifera.

\section{Optimal Density}

Our investigation showed that the suggestion of Breure (2010) to plant tenera material from Ghana origin at the same density of 160 palms ha $^{-1}$ appears to be premature. Clearly, optimal densities, as 
estimated in the present study, show a variation of 139 to 156 palms ha-1 among the offspring from individual Ghana pisifera parents. Such diversity in growth is surprising after four generations of inbreeding. With less inbred pisifera, the variation becomes substantially higher, as Breure (unpublished data) found, for example, for pisifera of Nigeria origin (124 to 157 palms ha-1). This novel outcome justifies our strategy of selecting individual pisifera for optimal planting density. Selected pisifera are cloned to ensure sufficient production of pollen.

One may argue that the optimal LAI obtained from the palm density experiment in PNG (cf. Breure, 1988) could be different from the optimum at the Kisaran site. However, environmental conditions at the PNG site, in terms of the proportion overcast and clear sky, the main factor influencing light penetration (Van Kraalingen et al., 1989), are similar to that at Kisaran, being $5.6 \mathrm{hr}$ per day bright sunshine at PNG versus $6 \mathrm{hr}$ at Kisaran.

It is, therefore, reasonable to adopt the optimal LAI value of 4.5 as obtained by Breure (1988) in order to estimate optimal densities of the individual Ghana pisifera in the present study. It should be noted that our focus is on differences in estimated optimum density between individual pisifera in one origin (Ghana). So even if there might be a slight difference in optimum LAI between the AVROS and Ghana origins, this would not affect the main objective of this study.

The present study still measures leaf area of individual palms for determining LAI at a mature canopy. With the modern technique of using LAI2000 palm canopy analyser (PCA), a more rapid non-destructive measurements of LAI can be made. However, Awal and Wan Ishak (2008) found that this method grossly overestimates LAI in young palms and underestimates LAI for palms older than six years. The LAI-2000 may thus only be used for comparing LAI values and not for estimating optimum palm density or the time to reach the optimum.

\section{Leaf Area}

Previous suggestions of applying early mean leaf area as an additional selection trait appear to be opposed. We obtained only a small relationship ( $\mathrm{r}=$ +0.18 ) between mean leaf area for the years two to five and L-max, confirming result of Breure (2010) for several pisifera origin. A difference in rate of leaf expansion is the main cause, as can be illustrated by a comparison of leaf expansion between P7 and P28. Both attain identical $0.95 \mathrm{~L}-\mathrm{max}$ values, but the plateau level occurs 2.4 years earlier for P7 than for P28, resulting in a much higher mean leaf area for P7 during years 2 to 5 (6.20 versus $5.09 \mathrm{~m}^{2}$ for P28).

\section{Yield Per Palm}

Our study confirms a strong negative correlation between mean yield per palm for the first seven years of production and cc-score ( $c f$. Figure 6), which implies that yield is related to the amount of light captured by the oil palm canopy, for which, as mentioned above, variation in leaf area is mainly responsible. At a density of 160 palms $\mathrm{ha}^{-1}$, as Breure suggested in his 2010 report, the most productive tenera palms from all Ghana pisifera may, therefore, later on exceed the optimum LAI. An LAI value for maximum yield per hectare that is higher than 4.5 ( $c f$. Figure 1) could occur for those pisifera parents that combine a high mean leaf area during canopy expansion with a high L-max value, such as, for example P30 and P11 (cf. Table 1). One way out is to select the palms during the period when the leaf surface has stabilised, for example, for the yield from years 6 to 9 of production, as adopted by the CIRAD system of selection (Durand-Gasselin et al., 2002). Besides the considerably delay before parent selection can take place, this method still only compares the individual palm production as that obtained at the density of the experiment. As a consequence, exploration of the potential yield per hectare remains outside scope. To circumvent this shortcoming, we determined planting densities that attain an optimum LAI of 4.5 at mature crown size. In order to correct the yield per palm (by linear interpolation) for the novel optimal planting densities, it is crucial to plant progeny trials at two commercial planting densities, as we did in the present study.

\section{Commercially-used Planting Densities}

It should be realised that our estimates of optimal planting densities can only be used as a guide for commercially-used densities, being 128, 135, 143, 151 and 160 palms ha-1. Slightly adjusting the estimated planting density to practical densities would virtually not affect the expected yield per hectare of the tenera produced. The reason is that the optimal yield per hectare has a fairly broad plateau across a range of densities (Corley and Tinker, 2016). For various reasons, it makes sense to increase our estimated density. First of all, Breure (1985) found that a higher planting density significantly reduced L-max, which is the key factor for determining optimal density. Second, although leaf area stabilises at a by and large fixed value, optimal density tends to increase again after the area of individual leaves reach the maximum level (Breure, 1988; Palat et al., 2012). Higher palm density would enlarge fruit set, and hence, percentages oil per bunch and kernel per bunch, as observed in various trials (Breure et al., 1990; Donough and Kwan, 1991; Rao et al., 1992; Nazeeb 
et al., 2007). The optimum for oil yield is, therefore, higher than that for bunch yield. Note also that higher density planting allows losses of palms in older plantings due to disease, for example, Ganoderma (Nazeeb et al., 2007).

A final point in favour of higher density than the levels estimated in this study is that, due to a lower LAI, the optimum density is higher during the period of leaf expansion before mature crown size $(0.95 \mathrm{~L}-\max )$ is reached. Such a situation is particularly relevant for those progenies having a relatively long period to attain $0.95 \mathrm{~L}$-max. Offspring from P28 is an example. The relatively long period of immature canopy $\left(\mathrm{t}_{0.95}\right)$ of P28 would increase the life time optimum more than, for example, offspring from P7 (Figure 5).

On the other hand, caution is required for areas that are prone to surface water run-off. Then a lower adjustment should be applied to ensure adequate ground vegetation in order to prevent substantial losses of top soil and applied fertilisers that are used. The full benefits of ground cover in mature plantings have been described, for example, by Giller and Fairhurst (2003).

The choice of the final density should, however, take into account the environmental conditions at the site. For palms growing in less optimal conditions than at our study, the mature leaf area (L-max) remains lower, resulting in higher optimal densities. Phang et al. (1977) showed, for example, that maximum leaf area considerably varies for inland soils in Malaysia, according to type and depth of the soil.

It could be argued that optimal density also depends on frond angle: For a total leaf surface, less light is captured when the frond angle is more erect (erectophyle) than horizontal (planophyle). However, Breure et al. (in preparation) found only minor differences between tenera offspring from six distinct pisifera origins in the degree at which light penetrating through the canopies is intercepted.

\section{Speed of Canopy Expansion}

The considerable difference in $t_{0.95}$ and hence, the period for reaching optimal density, is of interest. Breure (1985) compared single palms with slow and rapid crown expansion and found that the latter palms had a substantial higher bunch yield per palm during the first seven years of production. By shortening the time to reach optimal planting density through selection for rapid crown expansion, therefore, the cumulative yield for the entire life span would increase. Early plateau yield also allows quick financial returns and a more efficient use of the milling capacity, which are particularly important for newly established plantations. Moreover, rapid crown expansion reduces the costs for weeding the legume cover crop and makes planting at high density followed by the need for thinning a less useful option. In that respect, P7 with the shortest period of expansion would be a better parent than those with a slightly higher yield per hectare but higher $\mathrm{t}_{0.95}$ values ( $c f$. Table 1 ).

\section{CONCLUSION}

Pisifera parents are female-sterile, reason why their selection is based on the performance of their dura $\mathrm{x}$ pisifera (tenera) offspring. Yield per palm of tenera palms from individual pisifera parents show a highly significant inverse relationship with degree of light interception before canopy closure, as inferred from the vigor of the Mucuna ground vegetation (cc-score). In other words, relative darkness reigns under very productive palms. Since the cc-score shows a strongly negative correlation with mean leaf area, the conventional selection of individual pisifera for high yield per palm may produce tenera offspring that in later years exceed the optimal LAI, i.e. the total leaf surface per unit ground area for obtaining maximum yield per hectare. Otherwise, tenera from a less productive pisifera parent may not even reach the optimal LAI.

To circumvent this drawback, we estimated the planting densities that give optimal LAI at mature crown size. This optimum was reached at different periods after planting.

The ranking of the yield per hectare (of the offspring) at optimal density considerably deviates from that of the yield per palm, which is conventionally applied for selecting parent palms.

For the selection of pisifera parents, we recommend to focus on the yield per hectare of the tenera offspring and to shorten the period of attaining the optimal planting density by selection for rapid crown expansion.

\section{ACKNOWLEDGEMENT}

The authors are grateful to PT. ASD-Bakrie Oil Palm Seed Indonesia and PT. Bakrie Sumatera Plantations Tbk for permission to publish this article, and to Dr Verdooren, L R for his assistance in the crossing design and statistical analysis of the data. The assistance of E Susanto and A Q Zais Manza Lubis with the collection of data is acknowledged. Thanks are due to the staff of ASD for selecting the parents and generating the testcrosses, and to Dr Corley, R H V and Dr Keuss, P J G for their helpful comments and editorial assistance.

\section{REFERENCES}

Awal, M A and Wan Ishak (2008). Measurement of oil palm LAI by manual and LAI-2000 method. Asian J. Scientific Research, 1: 49-56. 
Breure, C J (1985). Relevant factors associated with crown expansion in oil palm (Elaeis guineensis Jacq.). Euphytica, 34: 161-175.

Breure, C J (1988). The effect of palm age and planting density on the partitioning of assimilates in oil palm (Elaeis guineensis Jacq.). Experimental Agriculture, 24: 53-66.

Breure, C J (2010). Rate of leaf expansion: A criterion for identifying oil palm (Elaeis guineensis Jacq.) types suitable for planting at higher densities. Wageningen J. Life Sciences, 57: 141-147.

Breure, C J (2017). Selection for physiological traits in oil palm. Oil Palm Breeding - Genetics and Genomics (Soh, A C; Mayes, S and Jeremy, R eds.). CRC Press, Taylor \& Francis Group, p. 87-95.

Breure, C J and Corley, R H V (1983). Selection of oil palms for high density planting. Euphytica, 32: 177186.

Breure, C J and Verdooren, L R (1995). Guidelines for testing and selecting parent palms in oil palm. Practical aspects and statistical methods. ASD Oil Palm Papers, 9: 1-68.

Breure, C J; Menendez, T and Powell, MS (1990). The effect of planting density on the yield components of oil palm (Elaeis guineensis Jacq.). Experimental Agriculture, 26: 117-124.

Corley, R H V; Hardon, J J and Tan, G Y (1971). Analysis of growth of the oil palm (Elaeis guineensis Jacq.). 1. Estimation of growth parameters and application in breeding. Euphytica, 20: 307-315.

Corley, R H V and Donough, C R (1992). Potential yield of oil palm clones - The importance of planting density. Proc. of the Workshop Yield Potential in the Oil Palm (Rao, V; Henson, I E and Rajanaidu, N eds.). International Society for Oil Palm Breeders, Kuala Lumpur. p. 58-70.

Corley, R H V and Tinker, P B (2016). The Oil Palm. Fifth edition. Willey Blackwel. Oxford. 674 pp.

Donough, C R and Kwan, B (1991). Oil palm planting density: Results from trials in Sabah and the possible options. Planter, 67: 483-508.

Durand-Gasselin, T; Cochard, B; De Franqueville, $\mathrm{H}$; Nouy, B; Potier, F; Louise, C; Amblard, P and Flori, A (2002). Merits of a pedigree selection cycle for the creation of elite oil palm (E. guineensis Jacq.). Paper presented at the 2002 International Oil Palm Conference. Indonesian Oil Palm Research Institute, Bali, Indonesia. 8-12 July 2002.
Foster, H L (2011). Report on Fertilizer Reecommendations for PT Bakrie Plantations Seed Gardens at Kisaran. 8 pp.

Gerritsma, W (1988). Light Interception, Leaf Photosynthesis and Sink-source Relations in Oil Palm. M.Sc thesis, Wageningen Agricultural University, Wageningen, The Netherlands. 74 pp.

Gerritsma, W and Soebagyo, F X (1999). An analysis of the growth of leaf area of oil palms in Indonesia. Experimental Agriculture, 35: 293-308.

Giller, K E and Fairhurst, T H (2003). Legume cover plants. The Oil Palm, Management for Large and Sustainable Yields (Fairhurst, T H and Härdter, R eds.). Potash \& Phosphate Institute (PPI), Potash \& Phosphate Institute of Canada (PPIC) and International Potash Institute (IPI). p. 151-161.

Hardon, J J; Williams, C N and Watson, I (1969). Leaf area and yield in the oil palm in Malaysia. Experimental Agriculture, 5: 25-32.

Hardon, J J; Corley, R H V and Ooi, S C (1972). Analysis of growth of oil palm. 2. Estimation of genetic variances of growth parameters and yield of fruit bunches. Euphytica, 21: 257-264.

Lövenstein, H; Lantinga, E A; Rabbinge, R and Van Keulen, H (1995). Principles of Production Ecology. Department of Theoretical Production Ecology, Wageningen Agricultural University, Wageningen, The Netherlands. 121 pp.

Nazeeb, M; Tang S G; Loong, S B and Syed Shahar Barakbah (2007). Variable density plantings for oil palms (Elaeis guineensis Jacq.) in Peninsular Malaysia. Proc. of the PIPOC 2007 International Palm Oil Congress - Palm Oil: Empowering Change. MPOB, Bangi. p. 127-167.

Palat, T; Chayawat, N and Corley, R H V (2012). Maximizing oil palm yield by high density planting and thinning. Planter, 88: 241-256.

Patterson, H D; Williams, E R and Hunter, E A (1978). Block designs for variety trials. J. Agricultural Science, 90: 395-400.

Phang, S E; Ooi, C; Chan, F and Menon, C N (1977). Influence of soil series and soil depth on vegetative growth and early FFB production of the oil palm (Elaeis guineensis Jacq.). International Development in Oil Palm (Earp, D A and Newall, W eds.). Incorporated Society of Planters, Kuala Lumpur. p. 153-166.

Rao, V; Rajainadu, N; Kushairi, A and Jalani, B S (1992). Density effects in the oil palm. Proc. of the 
Workshop Yield Potenital in the Oil Palm (Rao, V; Henson, I E and Rajanaidu, N eds.). International Society for Oil Palm Breeders, Kuala Lumpur. p. 7179 .

Sparnaaij, L D (1969). Oil palm - Elaeis guineensis Jacquin. Outlines of Perennial Crop Breeding in the Tropics (Ferwerda, F D and Wit, F eds.). Veenman and Zonen, Wageningen, The Netherlands. p. 339-387.

Sly, J M A and Chapas, L C (1963). The effect of various spacings on the first 16 years of growth and production of the Nigerian oil palm under plantation conditions. J. West Afr. Inst. Oil Palm Res., 4: 31-45.

Smith, B G; Donough, C R and Corley, R H V (1996). Relationship between oil palm clone phenotype and optimal planting density. Proc. of the 1996 PORIM International Palm Oil Congress - Competitiveness for the Twenty-first Century. PORIM, Bangi. p. 76-86.

Van Kraalingen, D W G; Breure, C J and Spitters, C J T (1989). Simulation of oil palm growth and yield. Agr. For. Meteorol., 46: 227-244. 